\title{
Molecular phylogeny and morphology of Pseudomallada (Neuroptera: Chrysopidae), one of the largest genera within Chrysopidae
}

\author{
PETER DUELLI ${ }^{1}$, CHARLES S. HENRY ${ }^{2 *}$, MASAYUKI HAYASHI $^{3}$, MASASHI NOMURA $^{3}$ \\ and ATSUSHI MOCHIZUKI ${ }^{4}$ \\ ${ }^{1}$ Biodiversity and Conservation Biology, Swiss Federal Research Institute WSL, Zürcherstrasse 111, \\ CH-8903 Birmensdorf ZH, Switzerland \\ ${ }^{2}$ Department of Ecology and Evolutionary Biology, University of Connecticut, Unit 3043, 75 North \\ Eagleville Road, Storrs, CT 06269-3043, USA \\ ${ }^{3}$ Laboratory of Applied Entomology, Chiba University, 648 Matsudo, Matsudo City, Chiba 271-8510, Japan \\ ${ }^{4}$ Biodiversity Division, Institute for Agro-Environmental Sciences NARO, 3-1-3 Kannondai, Tsukuba \\ City, Ibaraki 305-8604, Japan
}

Received 24 March 2016; revised 25 July 2016; accepted for publication 10 October 2016

\begin{abstract}
Pseudomallada, comprising at least 166 described species, is not only one of the most species-rich genera within the green lacewing family Chrysopidae but also one of the largest within the entire order Neuroptera. Using external morphology, it has not been possible to parse Pseudomallada into smaller taxonomic units such as subgenera or species-groups. Here, we examine morphology, life-history traits, and nuclear DNA sequences in 49 described or putative species of Pseudomallada from all over the world, including 2 closely related species currently assigned to Apertochrysa. On the one hand, we find that body and egg coloration, as well as the mode of egg deposition, have evolved independently within different genetic clusters of species in response to environmental conditions favouring cryptic behaviour or sibling cannibalism. However, three lineages supported by molecular phylogenetic analysis are congruent with three clusters based on the morphology of the gonapsis in the male genitalia; these comprise 29 of the taxa under study (59\%). Seventeen additional species cluster in a flavifrons-group based on gonapsis shape, but this cluster is not supported by molecular data. Three molecular singletons were identified, two of which can be assigned to one of the four gonapsis groups. It is clear that at least Apertochrysa eurydera, and probably A. edwardsi, should be moved into the genus Pseudomallada, based on molecular data and the shape of the gonapsis.
\end{abstract}

ADDITIONAL KEYWORDS: body colour - egg colour - morphology - oviposition - phylogeny - systematics - taxonomy.

\section{INTRODUCTION}

A detailed account of the actively changing history of the genus Pseudomallada Tsukaguchi was given by Dong et al. (2004). Navás (1925) established the genus Mallada and Nakahara (1955) the genus Anisochrysa, but at those times, the known species of the present genus Pseudomallada were still mostly called Chrysopa Leach. Adams (1975) realized that Anisochrysa was a synonym of Mallada, but for many years, the genus Anisochrysa was the home for

*Corresponding author. E-mail: charles.henry@uconn.edu various genera, including all present species of the genus Pseudomallada, as well as Mallada and sometimes even Chrysoperla Steinmann. Brooks \& Barnard (1990) used the genus name Mallada for the present genera Mallada and Pseudomallada, whereas Yang (1991) separated Mallada and coined the new genus name Dichochrysa. Brooks (1994) considered the new genus Dichochrysa to be the sister taxon to all other Chrysopini. In 1995, Tsukaguchi (1995) changed the genus name Dichochrysa to Pseudomallada. A subsequent petition to the International Commission on Zoological Nomenclature to conserve the genus name Dichochrysa was not approved, thus validating 
the name Pseudomallada for species formerly placed in Dichochrysa (Anonymous, 2010). The Lacewing Digital Library (LDL) (http://lacewing.tamu.edu/) currently includes at least 166 described species of Pseudomallada, making this not only one of the largest genera in the Chrysopidae but also one of the largest in the entire order Neuroptera.

With the help of molecular sequence data, the phylogenetic positions of some Pseudomallada species (still as Dichochrysa) within the family Chrysopidae were inferred by Winterton \& de Freitas (2006) and Haruyama et al. (2008). Its closest relatives among the Chrysopini were hypothesized to be Glenochrysa Esben-Petersen, Chrysopa, and Plesiochrysa Adams. Consequently, we have good evidence that Mallada s.s. and Pseudomallada are distant rather than close relatives, that Mallada is closely related to Chrysoperla, and that Pseudomallada as previously construed is not the sister taxon of all other Chrysopini.

In the present study, we tested the hypothesis that Pseudomallada is a monophyletic taxon (see Aspöck, Hölzel \& Aspöck, 2001) by examining nuclear DNA sequence data, genital morphology, body coloration, egg colour, and oviposition behaviour in 49 described or putative species of the genus from around the world. A principal goal was to find unique characters and patterns of sequence data shared by the numerous and often similar-looking species thought to comprise this giant taxon.

\section{MATERIAL AND METHODS}

\section{MOLECULAR METHODS}

For the molecular phylogenetic analysis, 85 neuropteran taxa were used, including a subset of the chrysopid species reported in Duelli, Henry \& Mochizuki (2014). Micromus linearis Hagen (Neuroptera: Hemerobiidae) served as the out-group (Table 1). Because we suspect a complex of cryptic species exists within Pseudomallada prasinus and $P$. abdominalis, we chose to analyze three individuals of $P$. prasinus and two individuals of $P$. abdominalis from different localities. Describing authors of each named species are given in Table 1.

Total genomic DNA was extracted from the thorax using a QuickGene DNA tissue kit S (WAKO, Tokyo, Japan) following the manufacturer's instructions. The thorax was removed from the specimen using a utility knife, homogenized with a plastic micro-pestle in extracting buffer (MDT + EDT), and incubated for $24-48 \mathrm{~h}$ at $55^{\circ} \mathrm{C}$.

Portions of the nuclear genes phosphoenolpyruvate carboxykinase (PepCK), wingless ( $w g)$, and sodium/ potassium ATPase alpha subunit (ATPase) were amplified by the same primers and PCR protocols as specified in a previous paper (Haruyama et al., 2008). The PCR reaction typically contained 1xLA Taq buffer
( $\mathrm{Mg}^{++}$free), $3 \mathrm{mM} \mathrm{MgCl}_{2}, 0.4 \mathrm{mM}$ dNTP mixture, $1 \mathrm{mM}$ of each primer, 1.25 units of TaKaRa Ex Taq, and $1 \mu \mathrm{L}$ of DNA solution.

Nested PCR protocols were performed for specimens that were difficult to amplify with these primers. Widerange primer sets were used for the first PCR: PEPCKmmF/PEPCK-wfR for the PepCK gene, WG1F2/LepWG2a for the $w g$ gene, and SodF13/ SodR13 for $410 \mathrm{bp}$ of the ATPase gene were used (Table 2). The amplification program was: $94{ }^{\circ} \mathrm{C}(1 \mathrm{~min}) ; 30$ cycles of $94{ }^{\circ} \mathrm{C}(30 \mathrm{~s}), 50{ }^{\circ} \mathrm{C}$ $(30 \mathrm{~s})$, and $72{ }^{\circ} \mathrm{C}(2 \mathrm{~min})$. The PCR reaction typically contained 1xLA Taq buffer $\left(\mathrm{Mg}^{++}\right.$free), $3 \mathrm{mM} \mathrm{MgCl}_{2}$, $0.4 \mathrm{mM}$ dNTP mixture, $1 \mathrm{mM}$ of each primer, 1.25 units of TaKaRa Ex Taq, and $1 \mu \mathrm{L}$ of DNA solution.

Following that, we diluted the first PCR product 50-fold with Double Distilled Water (DDW) and used 1 $\mu \mathrm{L}$ of the dilution solution as a template for the second PCR. The second PCR was performed using internal primer sets as follows: $511.2 \mathrm{drc} / 19.5 \mathrm{dF}$ for the $P e p C K$ gene, WG1-wm/WG2-2R and LepWG1/WG2.1 for the $w g$ gene, and SodinF/SodinR for $410 \mathrm{bp}$ of the ATPase gene (Table 2). The $w g$ gene was amplified by dividing it into two fragments.

The amplification program was as follows: $94^{\circ} \mathrm{C}$ (4 min); 4 cycles of $94^{\circ} \mathrm{C}(30 \mathrm{~s}), 51^{\circ} \mathrm{C}(30 \mathrm{~s})$, and $72^{\circ} \mathrm{C}$ $(1 \mathrm{~min} 20 \mathrm{~s})$; 36 cycles of $94{ }^{\circ} \mathrm{C}(30 \mathrm{~s}), 45^{\circ} \mathrm{C}(30 \mathrm{~s})$, and $72{ }^{\circ} \mathrm{C}(1 \mathrm{~min} 20 \mathrm{~s}) ; 72{ }^{\circ} \mathrm{C}(3 \mathrm{~min})$. The PCR reaction mixture contained $1 \mathrm{xEx}$ Taq buffer, $0.4 \mathrm{mM}$ dNTP mixture, $1 \mathrm{mM}$ of each primer, 1.25 units of TaKaRa Ex Taq, and $1 \mu \mathrm{L}$ of DNA solution.

We succeeded in amplifying the upstream region of the $410 \mathrm{bp}$ ATPase gene fragment. To do this, a Sod70F/ SodC170R primer set was used for the first PCR and a Sod150F/Sod90Rm was used for the second PCR. Amplification programs and contents of the reaction mixture were the same as for the other genes.

PCR products were checked using $1 \%$ agarose gel electrophoresis and purified by NucleoSpin Gel and PCR Clean-up (Takara Bio Inc., Otsu, Japan). If nonspecific bands were found, specific bands were excised prior to purification. The purified products were submitted to Greiner Bio-One Co. Ltd (Tokyo, Japan) for direct sequencing. Sequences were assembled using GENETYXMAC v15.0 (Genetyx Corporation, Tokyo, Japan). The $w g$ gene sequence was obtained by assembling the sequences of two PCR fragments (WG1-wm/WG2-2R and LepWG1/WG2.1). Nine hundred and eighteen base pairs of ATPase gene sequence were obtained by assembling the sequences of the $410 \mathrm{bp}$ ATPase gene and of the Sod150F/Sod90Rm PCR fragment. Accession numbers for the three nuclear gene sequences are given in Table 1.

\section{MOLECULAR PHYLOGENETIC ANALYSIS}

Phylogenetic trees were estimated using maximum likelihood (ML) and Bayesian inference (BI) on 
Table 1. List of specimens of Hemerobiidae and Chrysopidae used in this study, including accession numbers

\begin{tabular}{|c|c|c|c|c|}
\hline \multirow[t]{2}{*}{ Taxon } & \multicolumn{3}{|c|}{ DDBJ accession number } & \multirow[t]{2}{*}{ Collection data } \\
\hline & PepCK & $w g$ & ATPase & \\
\hline \multicolumn{5}{|l|}{ Hemerobiidae } \\
\hline Micromus linearis Hagen & AB287526 & AB287527 & AB287528 & $\begin{array}{l}\text { Japan, Chiba, } 23 \text { V. } 2004 \text {, } \\
\text { N. Haruyama }\end{array}$ \\
\hline \multicolumn{5}{|l|}{ Chrysopidae } \\
\hline \multicolumn{5}{|l|}{ Nothochrysinae } \\
\hline Kimochrysa africana (Kimmins) & AB287888 & AB287889 & AB287890 & $\begin{array}{l}\text { RSA, Bushmans Kloof, } 5 \\
\text { X. 2004, P. Duelli }\end{array}$ \\
\hline \multicolumn{5}{|l|}{ Apochrysinae } \\
\hline Anapochrysa voeltzkowi (Weele) & AB287882 & AB287883 & AB287884 & $\begin{array}{l}\text { RSA, Tsitsikamma, } 18 \text { II. } \\
\text { 2001, P. Duelli }\end{array}$ \\
\hline Apochrysa matsumurae (Okamoto) & $\mathrm{AB} 287532$ & AB287533 & $\mathrm{AB} 287534$ & $\begin{array}{l}\text { Japan, Chiba, } 19 \text { X. 2003, } \\
\text { N. Haruyama }\end{array}$ \\
\hline \multicolumn{5}{|l|}{ Chrysopinae } \\
\hline \multicolumn{5}{|l|}{ Ankylopterygini } \\
\hline Ankylopteryx gracilis Nakahara & $\mathrm{AB} 287915$ & AB287916 & AB287917 & $\begin{array}{l}\text { Japan, Okinawa, } 14 \text { XI. 2006, } \\
\text { I. Aoki }\end{array}$ \\
\hline Ankylopteryx octopunctata (Fabricius) & AB287538 & AB287539 & AB287540 & $\begin{array}{c}\text { Japan, Okinawa, } 19 \text { III. } \\
\text { 2004, N. Haruyama }\end{array}$ \\
\hline Semachrysa matsumurae (Okamoto) & AB287547 & AB287548 & AB287549 & $\begin{array}{c}\text { Japan, Okinawa, } 19 \text { III. } \\
\text { 2004, N. Haruyama }\end{array}$ \\
\hline \multicolumn{5}{|l|}{ Belonopterygini } \\
\hline Italochrysa italica (Rossi) & AB287553 & AB287554 & AB287555 & $\begin{array}{l}\text { France, Le Muy, } 9 \text { VIII. 1996, } \\
\text { P. Duelli }\end{array}$ \\
\hline Italochrysa nigrovenosa Kuwayama & AB287559 & AB287560 & AB287561 & $\begin{array}{l}\text { Japan, Osaka, } 9 \text { VII. 2005, } \\
\text { N. Haruyama }\end{array}$ \\
\hline \multicolumn{5}{|l|}{ Chrysopini } \\
\hline Apertochrysa edwardsi (Banks) & LC102755 & LC102780 & LC102805 & $\begin{array}{l}\text { Australia, Myara, WA, } 15 \text { XI. } \\
\text { 2000, J. B. Johnson and } \\
\text { P. Duelli }\end{array}$ \\
\hline Apertochrysa eurydera (Navás) & LC110411 & LC110412 & LC110413 & $\begin{array}{l}\text { Ghana, Lake Bosumtwe, } 13 \\
\text { IV. 2007, P. Duelli }\end{array}$ \\
\hline Atlantochrysa atlantica (McLachlan) & AB820321 & AB820322 & AB820323 & $\begin{array}{l}\text { Madeira, Porto Moniz, } \\
\text { Levada Janela, 11 IX. } \\
\text { 2001, P. Duelli }\end{array}$ \\
\hline Brinckochrysa kintoki (Okamoto) & $\mathrm{AB} 287574$ & AB287575 & AB287576 & $\begin{array}{l}\text { Japan, Chiba, } 20 \text { IX. 2004, } \\
\text { N. Haruyama }\end{array}$ \\
\hline Brinckochrysa turkanensis (Navás) & $\mathrm{AB} 287580$ & $\mathrm{AB} 287581$ & AB287582 & $\begin{array}{l}\text { RSA, WCP, Cederberg, } 2 \\
\text { X. 2004, P. Duelli }\end{array}$ \\
\hline Chrysemosa jeanneli (Navás) & AB287583 & $\mathrm{AB} 287584$ & AB287585 & $\begin{array}{l}\text { RSA, WCP, Cederberg, } 22 \text { II. } \\
\text { 2001, P. Duelli }\end{array}$ \\
\hline Chrysopa dorsalis Burmeister & AB287589 & $\mathrm{AB} 287590$ & AB287591 & $\begin{array}{l}\text { Spain, Ondarroa, } 17 \text { VI. } \\
\text { 2006, P. Duelli }\end{array}$ \\
\hline Chrysopa viridana Schneider & AB287631 & AB287632 & AB287633 & $\begin{array}{l}\text { Italy, Ferrara, } 21 \text { VI. 2005, } \\
\text { P. Duelli }\end{array}$ \\
\hline Chrysoperla carnea (Stephens) & $\mathrm{AB} 287643$ & AB287644 & $\mathrm{AB} 287645$ & Germany, commercial strain \\
\hline Chrysoperla comans (Tjeder) & AB287903 & AB287904 & AB287905 & $\begin{array}{l}\text { RSA, Drakensberg, Clarens, } \\
\text { 15 II. 2002, P. Duelli }\end{array}$ \\
\hline Chrysoperla furcifera (Okamoto) & AB287652 & AB287653 & AB287654 & $\begin{array}{l}\text { Japan, Chiba, } 9 \text { IX. 2003, } \\
\text { N. Haruyama }\end{array}$ \\
\hline Chrysoperla pudica (Navás) & AB287673 & AB287674 & AB287675 & $\begin{array}{l}\text { RSA, Cederberg, } 2 \text { X. 2004, } \\
\text { P. Duelli }\end{array}$ \\
\hline
\end{tabular}


Table 1. Continued

\begin{tabular}{|c|c|c|c|c|}
\hline \multirow[t]{2}{*}{ Taxon } & \multicolumn{3}{|c|}{ DDBJ accession number } & \multirow[t]{2}{*}{ Collection data } \\
\hline & PepCK & $w g$ & ATPase & \\
\hline Chrysotropia ciliata (Wesmael) & $\mathrm{AB} 287685$ & AB287686 & $\mathrm{AB} 287687$ & $\begin{array}{l}\text { Japan, Yamanashi, } 7 \text { VIII. } \\
\text { 2004, A. Mochizuki }\end{array}$ \\
\hline Cunctochrysa albolineata (Killington) & $\mathrm{AB} 287700$ & $\mathrm{AB} 287701$ & $\mathrm{AB} 287702$ & $\begin{array}{l}\text { France, Lourdes, } 19 \text { VI. 2006, } \\
\text { P. Duelli }\end{array}$ \\
\hline $\begin{array}{l}\text { Cunctochrysa kannemeyeri } \\
\text { (Esben-Petersen) }\end{array}$ & AB287891 & AB287892 & AB287893 & $\begin{array}{l}\text { RSA, WCP, Wolfdrift, } 1 \\
\text { X. 2004, P. Duelli }\end{array}$ \\
\hline Cuctochrysa baetica (Hölzel) & AB820324 & AB820325 & AB820326 & $\begin{array}{l}\text { France, Carcès VAR, } 23 \text { VII. } \\
\text { 2004, P. Duelli }\end{array}$ \\
\hline Mallada basalis (Walker) & $\mathrm{AB} 287808$ & AB287809 & AB287810 & Taiwan, lab-cultured strain \\
\hline Mallada desjardinsi Navás & $\mathrm{AB} 287811$ & $\mathrm{AB} 287812$ & $\mathrm{AB} 287813$ & $\begin{array}{l}\text { Japan, Chiba, } 10 \text { VIII. 2003, } \\
\text { N. Haruyama }\end{array}$ \\
\hline Mallada krakatauensis (Tsukaguchi) & $\mathrm{AB} 287826$ & $\mathrm{AB} 287827$ & $\mathrm{AB} 287828$ & $\begin{array}{l}\text { Japan, Hokkaido, } 19 \text { VIII. } \\
\text { 2005, N. Haruyama }\end{array}$ \\
\hline Meleoma arizonensis (Banks) & $\mathrm{AB} 287832$ & AB294231 & AB287833 & $\begin{array}{l}\text { USA, Arizona, } 7 \text { VIII. 2003, } \\
\text { P. Duelli }\end{array}$ \\
\hline Meleoma furcata (Banks) & AB287834 & AB287835 & AB287836 & $\begin{array}{l}\text { USA, Arizona, } 5 \text { VIII. 2003, } \\
\text { P. Duelli }\end{array}$ \\
\hline Meleoma titschacki Navás & LC104976 & LC104977 & LC104978 & $\begin{array}{l}\text { Nicaragua, Selva Negra, } \\
22 \text { X. 2009, P. Duelli, } \\
\text { U. Aspöck, and H. Aspöck }\end{array}$ \\
\hline Nineta itoi Tsukaguchi & AB287846 & AB287847 & AB287848 & $\begin{array}{l}\text { Japan, Yamanashi, } 7 \text { VIII. } \\
\text { 2004, A. Mochizuki }\end{array}$ \\
\hline Nineta pallida (Schneider) & AB287852 & $\mathrm{AB} 287853$ & AB287854 & $\begin{array}{l}\text { Switzerland, Zürich, } 19 \text { VII. } \\
\text { 2006, P. Duelli }\end{array}$ \\
\hline Peyerimhoffina gracilis (Schneider) & AB287867 & AB287868 & AB287869 & $\begin{array}{l}\text { Switzerland, Zürich, } 27 \text { VII. } \\
\text { 2006, P. Duelli }\end{array}$ \\
\hline Plesiochrysa lacciperda (Kimmins) & $\mathrm{AB} 287870$ & $\mathrm{AB} 287871$ & $\mathrm{AB} 287872$ & India, cultured strain \\
\hline Plesiochrysa ramburi (Schneider) & AB294225 & AB294226 & AB294227 & $\begin{array}{l}\text { Australia, Chichester, } 8 \text { XI. } \\
\text { 2000, P. Duelli }\end{array}$ \\
\hline $\begin{array}{l}\text { Pseudomallada abdominalis } \\
\text { (Brauer) (Switzerland) }\end{array}$ & LC102731 & LC102756 & LC102781 & $\begin{array}{l}\text { Switzerland, Agarone, } 17 \\
\text { V. 2015, P. Duelli }\end{array}$ \\
\hline $\begin{array}{l}\text { Pseudomallada abdominalis } \\
\quad \text { (Brauer) (Italy) }\end{array}$ & LC102732 & LC102757 & LC102782 & $\begin{array}{l}\text { Italy, Cisternino, } 30 \text { VI. 2015, } \\
\text { P. Duelli }\end{array}$ \\
\hline Pseudomallada alcestes (Banks) & AB287709 & AB287710 & $\mathrm{AB} 287711$ & $\begin{array}{c}\text { Japan, Okinawa, } 17 \text { III. } \\
\text { 2004, N. Haruyama }\end{array}$ \\
\hline Pseudomallada astur (Banks) & $\mathrm{AB} 287715$ & $\mathrm{AB} 287716$ & AB287717 & $\begin{array}{l}\text { Japan, Okinawa, VII. 2005, } \\
\text { I. Aoki }\end{array}$ \\
\hline Pseudomallada baronissus (Navás) & AB287718 & $\mathrm{AB} 287719$ & AB287720 & $\begin{array}{l}\text { RSA, Drakensberg, Clarens, } \\
13 \text { II. 2002, P. Duelli }\end{array}$ \\
\hline Pseudomallada benedictae (Séméria) & LC102733 & LC102758 & LC102783 & $\begin{array}{l}\text { France, Palaysan, } 9 \text { VIII. } \\
\text { 2006, P. Duelli }\end{array}$ \\
\hline Pseudomallada chloris (Schneider) & AB287721 & AB287722 & AB287723 & $\begin{array}{l}\text { RSA, Drakensberg, Clarens, } \\
15 \text { II. 2002, P. Duelli }\end{array}$ \\
\hline Pseudomallada clathratus (Schneider) & LC102734 & LC102759 & LC102784 & $\begin{array}{l}\text { Switzerland, Agarone, } 3 \text { IX. } \\
\text { 2013, P. Duelli }\end{array}$ \\
\hline Pseudomallada cognatellus (Okamoto) & AB287733 & AB287734 & AB287735 & $\begin{array}{l}\text { Japan, Kagoshima, } 17 \\
\text { X. 2005, N. Haruyama }\end{array}$ \\
\hline Pseudomallada duplicatus (Navás) & LC102735 & LC102760 & LC102785 & $\begin{array}{l}\text { Mauritius, Nouvelle } \\
\text { Decouverte, } 11 \text { XII. 2004, } \\
\text { P. Duelli }\end{array}$ \\
\hline
\end{tabular}


Table 1. Continued

\begin{tabular}{|c|c|c|c|c|}
\hline \multirow[t]{2}{*}{ Taxon } & \multicolumn{3}{|c|}{ DDBJ accession number } & \multirow[t]{2}{*}{ Collection data } \\
\hline & PepCK & $w g$ & ATPase & \\
\hline Pseudomallada flavifrons (Brauer) & $\mathrm{AB} 287736$ & $\mathrm{AB} 287737$ & $\mathrm{AB} 287738$ & $\begin{array}{l}\text { Italy, Ferrara, } 21 \text { VI. } 2005 \text {, } \\
\text { P. Duelli }\end{array}$ \\
\hline $\begin{array}{l}\text { Pseudomallada formosanus } \\
\quad \text { (Matsumura) }\end{array}$ & AB287739 & $\mathrm{AB} 287740$ & $\mathrm{AB} 287741$ & $\begin{array}{l}\text { Japan, Chiba, } 11 \text { IX. 2003, } \\
\text { N. Haruyama }\end{array}$ \\
\hline Pseudomallada genei (Rambur) & AB287894 & AB287895 & AB287896 & $\begin{array}{l}\text { Spain, Andalusia, } 2 \text { IX. 2001, } \\
\text { P. Duelli }\end{array}$ \\
\hline Pseudomallada gunvorae (Tjeder) & LC102736 & LC102761 & LC102786 & $\begin{array}{l}\text { RSA, Pretoria, } 17 \text { II. 2002, } \\
\text { P. Duelli }\end{array}$ \\
\hline Pseudomallada hamatus (Tjeder) & LC102737 & LC102762 & LC102787 & $\begin{array}{l}\text { RSA, Drakensberg, Mont- } \\
\text { Aux-Sources, } 28 \text { III. 2015, } \\
\text { P. Duelli, J. B. Johnson, } \\
\text { and M. W. Mansell }\end{array}$ \\
\hline Pseudomallada handschini (Navás) & LC102738 & LC102763 & LC102788 & $\begin{array}{l}\text { RSA, Tendele Camp, } 13 \text { II. } \\
\text { 2002, P. Duelli }\end{array}$ \\
\hline Pseudomallada ibericus (Navás) & $\mathrm{AB} 287745$ & $\mathrm{AB} 287746$ & $\mathrm{AB} 287747$ & $\begin{array}{l}\text { Spain, Andalusia Jaizkibel, } \\
14 \text { VI. 2006, P. Duelli }\end{array}$ \\
\hline $\begin{array}{l}\text { Pseudomallada inopinatus (Hölzel } \\
\text { and Ohm) }\end{array}$ & LC102739 & LC102764 & LC102789 & $\begin{array}{l}\text { France, La Réunion, } 28 \text { IX. } \\
\text { 2004, P. Duelli }\end{array}$ \\
\hline Pseudomallada inornatus (Navás) & LC102740 & LC102765 & LC102790 & $\begin{array}{l}\text { France, Prades, } 13 \text { VII. 2015, } \\
\text { P. Duelli }\end{array}$ \\
\hline Pseudomallada karooensis (Hölzel) & AB287748 & AB287749 & AB287750 & $\begin{array}{l}\text { RSA, WCP, Wolfdrift, } 2 \\
\text { X. 2004, P. Duelli }\end{array}$ \\
\hline $\begin{array}{l}\text { Pseudomallada kibonotoensis } \\
\quad \text { (van der Weele) }\end{array}$ & LC102741 & LC102766 & LC102791 & $\begin{array}{l}\text { RSA, Soutpansberg, } \\
\text { Limpopo, } 22 \text { III. 2015, } \\
\text { P. Duelli, J. B. Johnson, } \\
\text { and M. W. Mansell }\end{array}$ \\
\hline Pseudomallada luaboensis (Tjeder) & LC102742 & LC102767 & LC102792 & $\begin{array}{l}\text { Ghana, Cape Coast, } 8 \text { IV. } \\
\text { 2007, U. Aspöck and } \\
\text { H. Aspöck }\end{array}$ \\
\hline Pseudomallada luctuosus (Banks) & $\mathrm{AB} 287751$ & $\mathrm{AB} 287752$ & AB287753 & $\begin{array}{l}\text { USA, Texas, } 2 \text { VIII. 2003, } \\
\text { P. Duelli }\end{array}$ \\
\hline $\begin{array}{l}\text { Pseudomallada macleodi (Adams } \\
\text { and Garland) }\end{array}$ & LC102743 & LC102768 & LC102793 & $\begin{array}{l}\text { USA, Arizona, } 7 \text { VIII. 2003, } \\
\text { P. Duelli }\end{array}$ \\
\hline Pseudomallada marianus (Navás) & LC102744 & LC102769 & LC102794 & $\begin{array}{l}\text { Switzerland, Agarone, } 15 \text { IX. } \\
\text { 2015, P. Duelli }\end{array}$ \\
\hline Pseudomallada sp. gray & LC102746 & LC102771 & LC102796 & $\begin{array}{l}\text { RSA, WCP, Cederberg, } 2 \\
\quad \text { X. 2005, P. Duelli }\end{array}$ \\
\hline Pseudomallada sp. Sodere & LC102747 & LC102772 & LC102797 & $\begin{array}{l}\text { Ethiopia, Sodere, } 26 \text { IV. 2003, } \\
\text { P. Duelli }\end{array}$ \\
\hline Pseudomallada nicolainus (Navás) & AB287757 & $\mathrm{AB} 287758$ & AB287759 & $\begin{array}{l}\text { RSA, Kuruman, } 29 \text { IX. 2004, } \\
\text { P. Duelli }\end{array}$ \\
\hline $\begin{array}{l}\text { Pseudomallada myassalandicus } \\
\text { (Navás) }\end{array}$ & LC102748 & LC102773 & LC102798 & $\begin{array}{l}\text { RSA, Soutpansberg, } \\
\text { Limpopo, } 22 \text { III. 2015, } \\
\text { P. Duelli, J. B. Johnson, } \\
\text { and M. W. Mansell }\end{array}$ \\
\hline Pseudomallada parabolus (Okamoto) & $\mathrm{AB} 287760$ & AB287761 & AB287762 & $\begin{array}{l}\text { Japan, Iwate, } 7 \text { VIII. } 2004 \text {, } \\
\text { N. Haruyama }\end{array}$ \\
\hline Pseudomallada perfectus (Banks) & AB287766 & AB287767 & AB287768 & $\begin{array}{l}\text { USA, Arizona, } 5 \text { VIII. 2003, } \\
\text { P. Duelli }\end{array}$ \\
\hline Pseudomallada perpallidus (Tjeder) & AB287769 & AB287770 & AB287771 & $\begin{array}{l}\text { RSA, Drakensberg, Clarens, } \\
16 \text { II. 2002, P. Duelli }\end{array}$ \\
\hline
\end{tabular}


Table 1. Continued

\begin{tabular}{|c|c|c|c|c|}
\hline \multirow[t]{2}{*}{ Taxon } & \multicolumn{3}{|c|}{ DDBJ accession number } & \multirow[t]{2}{*}{ Collection data } \\
\hline & PepCK & $w g$ & ATPase & \\
\hline Pseudomallada picteti (McLachlan) & LC102749 & LC102774 & LC102799 & $\begin{array}{l}\text { Spain, Puentelassa, } 19 \text { VI. } \\
\text { 2007, P. Duelli }\end{array}$ \\
\hline $\begin{array}{l}\text { Pseudomallada prasinus } \\
\text { (Burmeister) (Japan) }\end{array}$ & $\mathrm{AB} 287775$ & $\mathrm{AB} 287776$ & AB287777 & $\begin{array}{l}\text { Japan, Nagano, } 9 \text { VIII. 2003, } \\
\text { N. Haruyama }\end{array}$ \\
\hline $\begin{array}{l}\text { Pseudomallada prasinus } \\
\text { (Burmeister) (Greece) }\end{array}$ & LC102750 & LC102775 & LC102800 & $\begin{array}{l}\text { Greece, lab rearing, M. L. } \\
\text { Pappas }\end{array}$ \\
\hline $\begin{array}{l}\text { Pseudomallada prasinus (Burmeister) } \\
\quad \text { (Switzerland) }\end{array}$ & $\mathrm{AB} 287778$ & AB287779 & $\mathrm{AB} 287780$ & $\begin{array}{l}\text { Switzerland, Leuk, } 3 \text { V. 2006, } \\
\text { P. Duelli }\end{array}$ \\
\hline Pseudomallada pulchrinus (Tjeder) & LC102751 & LC102776 & LC102801 & $\begin{array}{l}\text { RSA, Soutpansberg, } 21 \text { III. } \\
\text { 2015, P. Duelli }\end{array}$ \\
\hline Pseudomallada rubicundus (Hölzel) & $\mathrm{AB} 287781$ & AB287782 & AB287783 & $\begin{array}{l}\text { RSA, WCP, Gamkaskloof, } 15 \\
\text { II. 2001, P. Duelli }\end{array}$ \\
\hline $\begin{array}{l}\text { Pseudomallada sjostedti } \\
\quad \text { (van der Weele) }\end{array}$ & AB287897 & AB287898 & AB287899 & $\begin{array}{l}\text { Ethiopia, Wendo Genet, } 13 \\
\text { IV. 2003, P. Duelli }\end{array}$ \\
\hline Pseudomallada sp.1 & AB287784 & $\mathrm{AB} 287785$ & AB287786 & $\begin{array}{l}\text { Japan, Okinawa, VI. 2005, } \\
\text { I. Aoki }\end{array}$ \\
\hline Pseudomallada sp.2 & AB287787 & AB287788 & AB287789 & $\begin{array}{l}\text { Japan, Okinawa, VI. 2005, } \\
\text { I. Aoki }\end{array}$ \\
\hline Pseudomallada spissinervis (Tjeder) & LC102752 & LC102777 & LC102802 & $\begin{array}{l}\text { RSA, WCP, Gamkaskloof, } 14 \\
\text { II. 2001, P. Duelli }\end{array}$ \\
\hline Pseudomallada tactus (Navás) & $\mathrm{AB} 287790$ & AB287791 & AB287792 & $\begin{array}{l}\text { RSA, WCP, Wolfdrift, } 2 \\
\quad \text { X. 2004, P. Duelli }\end{array}$ \\
\hline Pseudomallada ussuriensis (Makarkin) & AB287802 & AB287803 & AB287804 & $\begin{array}{l}\text { Japan, Iwate, } 7 \text { VIII. 2004, } \\
\text { N. Haruyama }\end{array}$ \\
\hline Pseudomallada venosus (Rambur) & LC102753 & LC102778 & LC102803 & $\begin{array}{l}\text { Georgia, Vardzia, } 15 \text { VIII. } \\
\text { 2013, D. Bolt and P. Duelli }\end{array}$ \\
\hline Pseudomallada ventralis (Curtis) & LC102754 & LC102779 & LC102804 & $\begin{array}{l}\text { Switzerland, Agarone, } 10 \text { IX. } \\
\text { 2008, P. Duelli }\end{array}$ \\
\hline Pseudomallada zelleri (Schneider) & AB287805 & AB287806 & AB287807 & $\begin{array}{l}\text { Switzerland, Agarone, } 14 \\
\text { V. 1999, P. Duelli }\end{array}$ \\
\hline Suarius walsinghami Navás & AB287873 & AB287874 & $\mathrm{AB} 287875$ & $\begin{array}{l}\text { Spain, Alhaurin de la Torre, } \\
2 \text { IX. 2001, P. Duelli }\end{array}$ \\
\hline Yumachrysa apache (Banks) & AB287876 & AB287877 & AB287878 & $\begin{array}{l}\text { USA, New Mexico, } 13 \text { VIII. } \\
\text { 2003, P. Duelli }\end{array}$ \\
\hline
\end{tabular}

ATPase, sodium/potassium ATPase alpha subunit gene; PepCK, phosphoenolpyruvate carboxykinase gene; $w g$, wingless gene.

combined DNA sequence data. Alignment of proteinencoding genes was inferred manually with reference to translated amino acid sequences using MUSCLE (Edgar, 2004a, b) in MEGA v6.06 (Tamura et al., 2013). Some amino acid insertions and deletions were found, but only in wingless ( $w g$ ) gene sequences.

The alignment for the combined DNA data was partitioned by codon position for each gene and a separate partition-specific substitution model was determined using the greedy algorithm in PARTITIONFINDER v1.1 (Lanfear et al., 2012). The best partitioning scheme and substitution models are given in Table 3 .

ML analyses were performed using RAxML (Stamatakis, 2014). The ML tree was generated using
1000 bootstrap replicates to evaluate statistical confidence at each branch (Felsenstein, 1985).

MRBAYES v3.2.1 (Ronquist et al., 2012) was used for dedicated BI phylogenetic analysis of the data. The Markov chain Monte Carlo analysis ran for 6.2 million generations. The Average Standard Deviation of Split Frequencies was 0.007 at the end of the analysis. Trees were sampled every 500 generations, discarding the first $25 \%$ of trees as burn-in. We confirmed with TRACER v1.6 (Rambaut et al., 2014) that Estimated Sample Size for all parameters was more than 200. In the BI analysis, posterior probabilities (PP) were calculated to evaluate statistical confidence at each node. 
Table 2. Primers used for nested PCR to extract and amplify DNA from specimens listed in Table 1

\begin{tabular}{|c|c|c|c|}
\hline Gene & Primer name & Sequence $\left(5^{\prime}-3^{\prime}\right)$ & Reference \\
\hline & Wide ranged primer & & \\
\hline \multirow[t]{2}{*}{ PepCK } & PEPCK-mmF & TGYGGNAARACNAAYYTNGCNATGATG & \\
\hline & PEPCK-wfR & TCNGCRTCNGCRTCYTTNCKRAACCA & \\
\hline \multirow[t]{2}{*}{$w g$} & WG1F2 & CARGARTGYAARTGYCAYGGNATG & \\
\hline & LepWG2a & ACTICGCARCACCARTGGAATGTRCA & Brower \& DeSalle (1998) \\
\hline \multirow[t]{5}{*}{ ATPase } & SodF13 & CTATGGTTRGATGCCGTTATCTT & Haruyama et al. (2008) \\
\hline & SodR13 & GGAATTTCRCANACTTTCTT & Haruyama et al. (2008) \\
\hline & Sod70F & CCNCCNAARCARACNCCNGARTGGTA & \\
\hline & SodC170R & TCRATRATTTGRTTRTCRAACCACAT & \\
\hline & Internal primer & & \\
\hline \multirow[t]{2}{*}{$P e p C K$} & $511.2 \mathrm{drc}$ & GGMCGCATTGCRAAYGGRTCGTGCAT & Modified a sequence of Friedlander et al. (1996) \\
\hline & $19.5 \mathrm{dF}$ & GGNGAYGAYATIGCBTGGATG & Friedlander et al. (1996) \\
\hline \multirow[t]{4}{*}{$w g$} & WG1-wm & TGYACNGTNAARACNTGYTGGATG & \\
\hline & WG2-2R & TTRCAYTTNACYTCRCARCACCA & \\
\hline & LepWG1 & GARTGYAARTGYCAYGGYATGTCTGG & Brower \& DeSalle (1998) \\
\hline & WG2.1 & CGATAHCCHCGNCCRCAACACA & \\
\hline \multirow[t]{4}{*}{ ATPase } & SodinF & CTTCCTTATTGGTATCATTGTAGC & \\
\hline & SodinR & CGCGACTTTCTTGTTGCGYTTACG & \\
\hline & Sod150F & ATHATGGARWSNGGNAARAAYATGGT & \\
\hline & Sod90Rm & GARCCYARNGTTTCYACAGCTTC & \\
\hline
\end{tabular}

ATPase, sodium/potassium ATPase alpha subunit gene; PepCK, phosphoenolpyruvate carboxykinase gene; $w g$, wingless gene. $\mathrm{B}=\mathrm{C}$ or $\mathrm{G}$ or $\mathrm{T}, \mathrm{H}=\mathrm{A}$ or $\mathrm{C}$ or $\mathrm{T}, \mathrm{M}=\mathrm{A}$ or $\mathrm{C}, \mathrm{N}=\mathrm{A}$ or $\mathrm{C}$ or $\mathrm{G}$ or $\mathrm{T}, \mathrm{K}=\mathrm{G}$ or $\mathrm{T}, \mathrm{R}=\mathrm{A}$ or $\mathrm{G}, \mathrm{S}=\mathrm{G}$ or $\mathrm{C}, \mathrm{W}=\mathrm{A}$ or $\mathrm{T}, \mathrm{Y}=\mathrm{T}$ or $\mathrm{C}, \mathrm{I}=$ inosine.

Evolutionary divergences among selected taxa and clades of taxa were estimated as the number of base substitutions per site averaged over all sequence pairs between the taxa or clades. Method of analysis was uncorrected $P$-distances as implemented in MEGA v6.06.

\section{GENITAL MORPHOLOGY}

Published drawings of male genitalia were available for most of the taxa sequenced. The most important sources were Tjeder (1966), Tsukaguchi (1995), Aspöck, Aspöck, \& Hölzel (1980), Hölzel (1993), Hölzel \& Ohm (1995, 2000), Adams \& Garland (1982), New (1980), and Brooks \& Barnard (1990). Many of the taxa were also available from the authors' collections and from fresh material collected for genetic analyses. Male abdomens of those species were kept in a warm $\mathrm{KOH}$ solution for several hours and then dissected and viewed under a Leica APO binocular microscope $(\times 80-\times 800)$. The male genitalia generally used for species descriptions in the genus Pseudomallada are the gonarcus with the arcessus, gonapsis, and tignum.

\section{BODY AND EGG COLORATION AND MODE OF OVIPOSITION}

While the colour of the body was known in most species treated here, only for less than half of the species had the mode of egg deposition been previously described in the literature. Most species were reared in lab cultures to obtain information on their eggs and larval stages. Moreover, the offspring could be used for sequence analysis and to obtain information on male genitalic morphology.

The following criteria were used to describe body coloration, egg colour, and mode of egg deposition:

\section{Body coloration}

Most Pseudomallada species are basically green, marked in Figure 1 by green rectangles. Some are bright green (Fig. 2A), others bluish green, and some have brown markings or bands on the thorax, but as long as the general aspect is green, they are listed here as green. A minority of species, mostly from hot and dry habitats, are grey or brown without any green (see Fig. 2B). They are listed as grey here and marked in Figure 1 by yellow rectangles.

\section{Egg colour}

Egg colour was recorded 1 day after oviposition, under full-spectrum illumination (daylight). Eggs can be plain green, light green, or bluish green (green circles in Fig. 1) or white, beige, or grey (white circles in Fig. 1). 
Table 3. Optimal data partitions and best nucleotide substitution models selected by PARTITIONFINDER v1.1 (Lanfear et al., 2012) to infer phylogenetic relationships of species listed in Table 1

\begin{tabular}{lll}
\hline Subset & $\begin{array}{l}\text { Subset partitions (nuclear } \\
\text { genes and codon positions) }\end{array}$ & Best model \\
\hline 1 & PepCK pos.1 & $\mathrm{TIM}+\mathrm{I}+\Gamma$ \\
2 & PepCK pos.2, wg pos.1, wg pos.2 & $\mathrm{HKY}+\mathrm{I}+\Gamma$ \\
3 & PepCK pos.3, ATPase pos.3 & $\mathrm{HKY}+\mathrm{I}+\Gamma$ \\
4 & wg pos.3 & $\mathrm{TVM}+\mathrm{I}+\Gamma$ \\
5 & ATPase pos.1 & $\mathrm{GTR}+\mathrm{I}+\Gamma$ \\
6 & ATPase pos.2 & $\mathrm{JC}+\mathrm{I}+\Gamma$ \\
\hline
\end{tabular}

ATPase, sodium/potassium ATPase alpha subunit gene; PepCK, phosphoenolpyruvate carboxykinase gene; $w g$, wingless gene.

\section{Oviposition mode}

Most Pseudomallada species deposit their eggs singly, on silken stalks. Other species in the genus exhibit bundled egg stalks (Fig. 2C). Some species deposit their eggs closely spaced in groups or in rows, but those are nevertheless treated here as laying single eggs. All known modes of oviposition in chrysopids are presented in Duelli (1984).

\section{RESULTS}

\section{MOLECULAR PHYLOGENY}

The combined DNA sequence length of the alignment was $1926 \mathrm{bp}$, comprising $483 \mathrm{bp}$ of $P e p C K, 525 \mathrm{bp}$ of $w g$, and $918 \mathrm{bp}$ of ATPase.

Phylograms of Chrysopidae show the Bayesian tree (Supporting Information, Fig. S1) with nodes labelled by PP and the ML tree (Supporting Information, Fig. S2) with nodes labelled by bootstrap values. Only values of PP above 0.8 and of bootstraps above $50 \%$ are included.

Our DNA sequence data analysis united 47 Pseudomallada taxa and two Apertochrysa species, A. eurydera and A. edwardsi, in a single clade ( $\mathrm{PP}=$ 0.99 , ML bootstrap values $=89 \%$ for combined data). We call this clade Pseudomallada s.l. Sub-trees of the taxa within the Pseudomallada s.l. are shown in Figure 1.

The species in Pseudomallada s.l. were allocated to two clades. The first clade, P1, included P. astur, $P$. alcestes, two unknown Japanese species ( $P$. sp. 1 and $P$. sp. 2), A. eurydera, P. cognatellus, $P$. parabolus, $P$. formosanus, $P$. ussuriensis, $P$. pulchrinus, $P$. duplicatus, and P. sjostedti $(\mathrm{PP}=1.00$, bootstrap $80 \%)$. The second clade, $\mathrm{P} 2$, included all the remaining species except $A$. edwardsi and $P$. inornatus ( $\mathrm{PP}=1.00$, bootstrap 84\%). Pseudomallada inornatus was supported as the sister taxon of the $\mathrm{P} 2$ clade $(\mathrm{PP}=0.99$, bootstrap $81 \%$ ). The phylogenetic position of A. edwardsi within Pseudomallada was unresolved. The P2 clade was divided further into two sub-clades, $\mathrm{P} 3$ and $\mathrm{P} 4$. The P3 clade included P. benedictae, $P$. zelleri, $P$. ventralis, $P$. prasinus, $P$. abdominalis, and $P$. marianus $(\mathrm{PP}=1.00$, bootstrap 93\%). The $\mathrm{P} 4$ clade included the rest of the species, except $A$. edwardsi and P. inornatus $(\mathrm{PP}=1.00$, bootstrap 96\%). Moreover, $P$. venosus, $P$. sp. Sodere, $P$. rubicundus, $P$. tactus, $P$. nicolainus, $P$. karooensis, $P$. genei, and $P$. clathratus formed a wellsupported additional clade, $\mathrm{P} 5$, within $\mathrm{P} 4(\mathrm{PP}=1.00$, bootstrap 97\%). Pseudomallada inopinatus appeared to be the sister taxon to the P5 clade ( $\mathrm{PP}=0.96$, bootstrap $82 \%$ ).

We then compared the molecular phylogenetic results with some morphological traits.

\section{GENITAL MORPHOLOGY}

Published figures and/or new drawings of male genital structures of 48 taxa were analyzed for quantifiable characters. For only one species ( $P$. sp. 1 from Japan), no genital structures were available, because only one unidentified female of that species was collected, and she laid no eggs.

The gonarcus, arcessus, and tignum are sclerotized structures just above the anus. The tignum was present in all nominal Pseudomallada species examined, but not in A. eurydera or A. edwardsi. It was a uniform structure throughout the genus and yielded no quantifiable measurements for sorting the species. The gonarcus and arcessus, on the other hand, are rather complex three-dimensional structures. However, they also were basically the same in most Pseudomallada species. Moreover, the quality of published drawings is too variable to make quantitative comparisons to previously described species. The situation is different for the gonapsis, a horizontal structure just below the anus, where clear differences between groups of species were discernible. All available graphics from literature and new preparations were sorted for visual similarity. Figure 3 shows the four icons to illustrate the general shape of the four main gonapsis types and the two measured structures we call here 'stem' and 'wings'.

G1: The synapomorphy of the 'dancer' shaped gonapsis (Fig. 3) is the frontally bifurcated 'stem'. The frontal 'wings' are broad, sometimes curled, and variable in size and shape. All taxa of the molecular phylogenetic clade P1 belonged to this 'dancer' group G1 (G for gonapsis). We call G1/P1 the alcestes-group, because $P$. alcestes is a wellknown and widespread species exemplifying the group icon. 

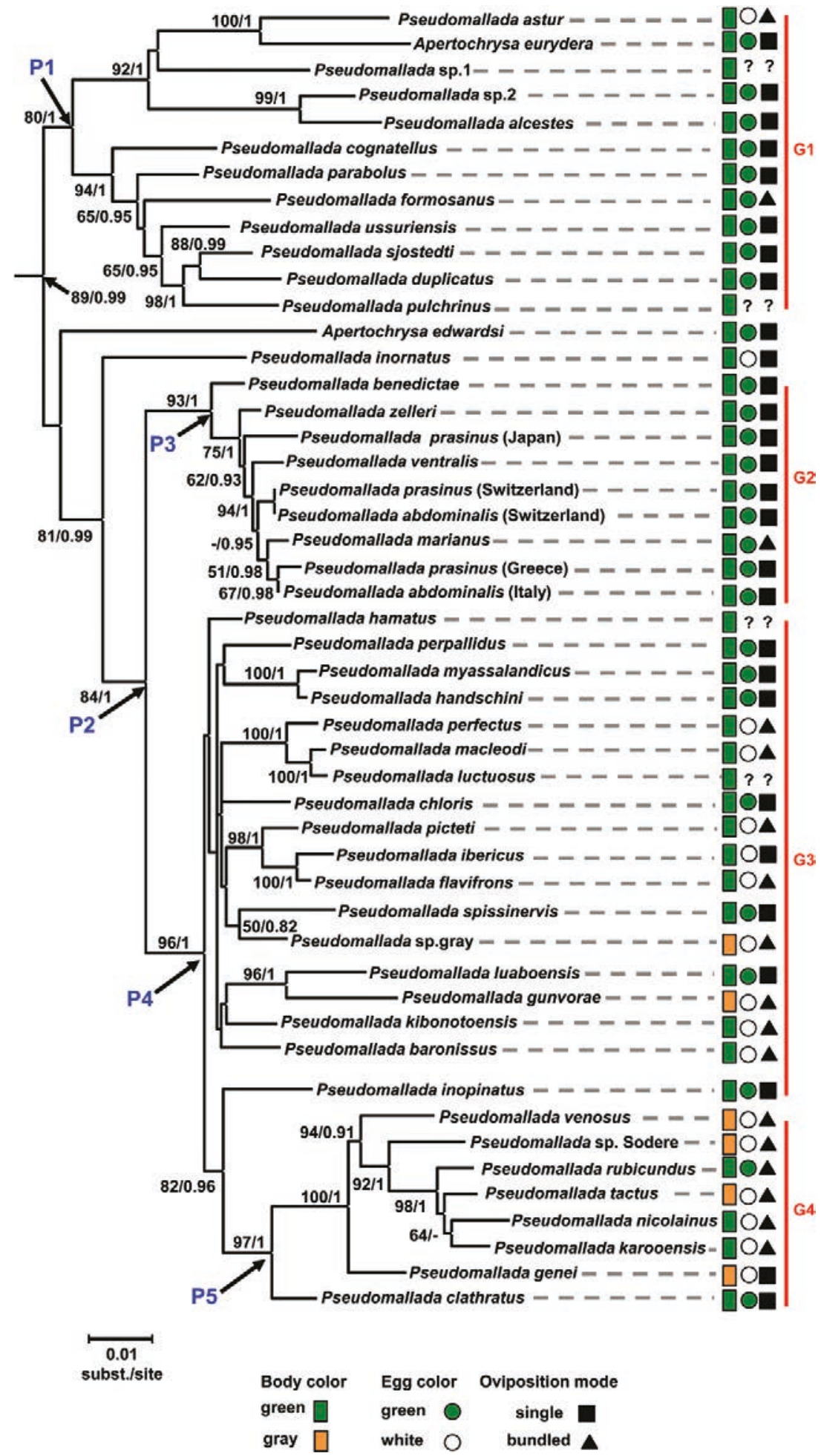

Figure 1. Maximum likelihood (ML) tree for Pseudomallada s.l. The tree is inferred from a combined analysis of three nuclear genes. The total sequence length of the alignment was $1926 \mathrm{bp}$, comprising $483 \mathrm{bp}$ of PepCK, $525 \mathrm{bp}$ of $w g$, and $918 \mathrm{bp}$ of ATPase. Values placed on each node are ML bootstrap values $\geq 50 \%$ /Bayesian posterior probabilities (PP) $\geq 0.80$. Dashes (-) mark branches with less than 0.80 PP or less than $50 \%$ bootstrap support. Body colour, egg colour and oviposition mode for each taxon are shown to the right of the tree. P1-P5: five major clades inferred from DNA sequences. G1-G4: four major gonapsis species-groups based on the general shape classes of male genitalia shown as icons in Figure 3. 

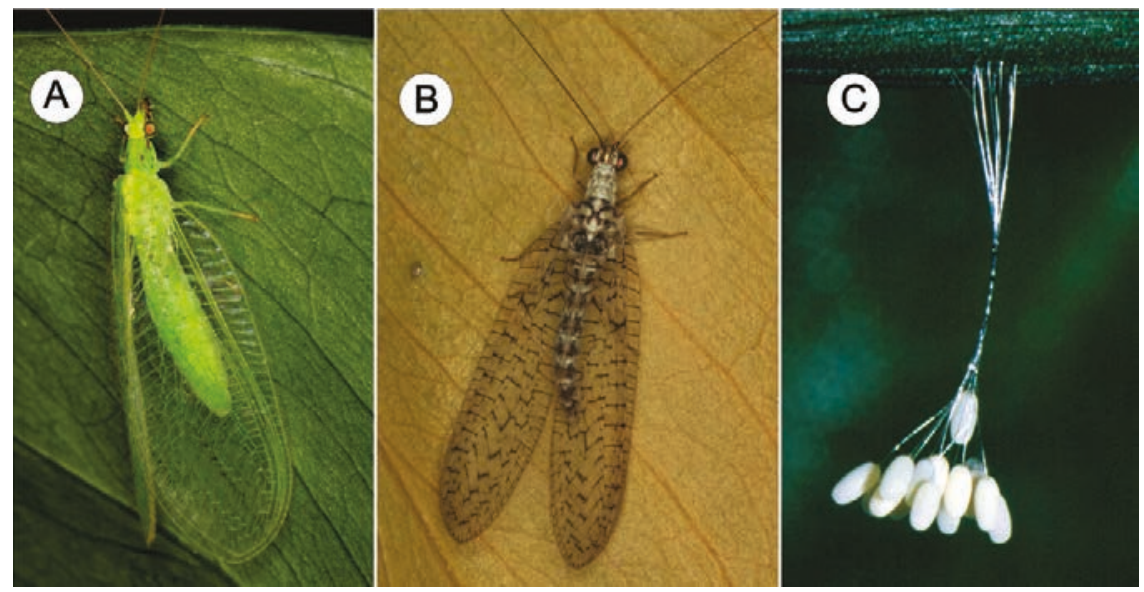

Figure 2. Photographs from life of (A) green Pseudomallada chloris from South Africa, (B) grey/brown Pseudomallada venosus from Georgia, and (C) bundled egg pedicels of $P$. venosus.

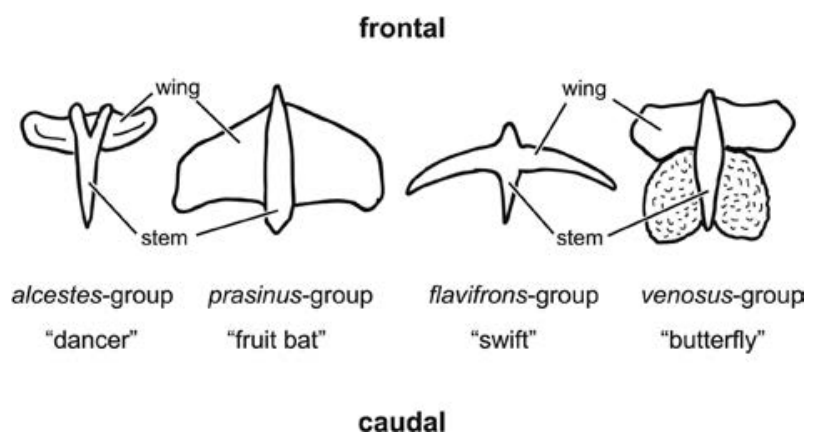

Figure 3. Icons classifying the general shape of the gonapsis of the male genitalia of Pseudomallada s.l. into four distinct groups. Each of the four gonapsis species-groups is named after the most widespread or best known species in the group. Icon names are meant to simplify complex descriptions.

G2: The gonapsis of this group is similar to that of G3, but the 'wings' are broader in G2, reminiscent of the shape of a fruit bat (Fig. 3). At the base, they are at least twice as broad as the 'stem'. A synapomorphy of this group of species, congruent with the clade P3, is the black dot between the antennae. Some species from other groups may also exhibit an inter-antennal dot, but in those it was brown or reddish. We call G2/ P3 the prasinus-group.

G3: The 'swift' icon (Fig. 3) in this group is characterized by slender 'wings'. At their base, they are less than twice as broad as the 'stem'. In some species, the 'wings' appeared to be covered by a veil, making them look broader. The group constitutes a part of the clade $\mathrm{P} 4$, but it is not supported by molecular data, nor did we find any clear synapomorphy uniting its members. We call G3 the flavifrons-group.
G4: The synapomorphy of the 'butterfly' shaped gonapsis (Fig. 3) is the unique appearance of the two wing pairs: the caudal 'wings' are always speckled and more rounded than the frontal ones. Group G4 is congruent with clade P5. We call G4/P5 the venosus-group.

The phylogenetic singleton A. edwardsi did not fit into any of the molecular phylogenetic clades. It is the only Australian species included in this study. It clearly belongs to Pseudomallada but lacks a tignum. However, the morphology of the gonapsis of A. edwardsi (Fig. 4A) was most similar to that seen in G1.

Another phylogenetic singleton is $P$. inornatus. The shape of the tiny gonapsis of P. inornatus (Fig. 4B) is markedly different from all four icons shown in Figure 3.

The gonapsis of $P$. inopinatus from the island of $\mathrm{La}$ Réunion (Fig. 4C) has only one pair of 'wings' and more of a 'swift' shape, resembling the condition seen in the flavifrons-group (G3).

\section{BODY COLORATION}

Of the 49 taxa examined for their body colour, 43 (88\%) are green. All species belonging to gonapsis groups G1 and G2 are green. Six species (12\%) have a body coloration between grey and yellowish brown. All grey or brown species are in the $\mathrm{P} 4$ clade, but in different clusters with mixed body coloration in gonapsis groups G3 and G4.

\section{EGG COLOUR}

Mode of egg deposition and egg colour are known from 45 of the 49 taxa treated here. Twenty-eight of those 45 taxa (62\%) deposit green eggs, ranging from bright 


\section{A. Apertochrysa edwardsi}

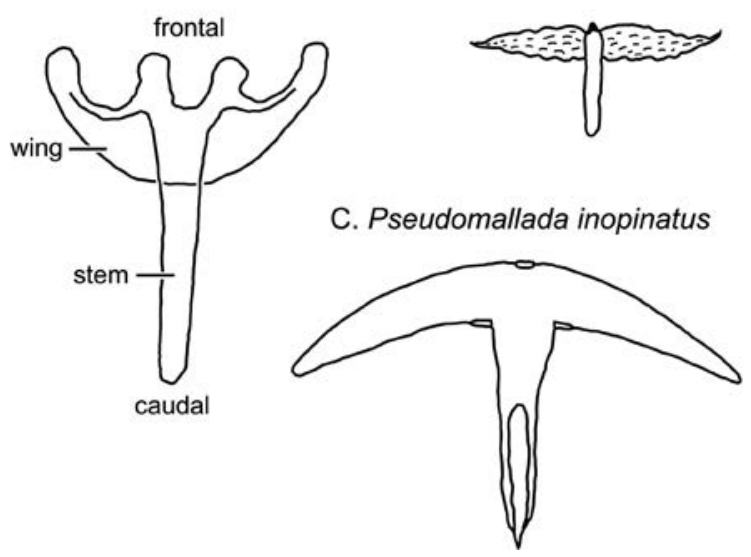

Figure 4. Gonapses of singletons that do not fall within the major molecular clades shown in Figure 1. (A) Apertochrysa edwardsi, (B) Pseudomallada inornatus, and (C) Pseudomallada inopinatus.

yellowish green to dark blue green. Seventeen taxa (38\%) deposit white eggs, which can be plain white, beige or greyish, but without any green.

White eggs are distributed across all groups except clade P3 and gonapsis group G2. All species with a grey or brown body deposit white eggs, but nine taxa with a green body colour also deposit white eggs.

\section{MODE OF EGG DEPOSITION}

Eggs are often deposited singly on a pedicel (28 of 45 taxa, $62 \%$ ), either isolated or in groups or rows. Other species deposit eggs in bundles with loosely or tightly connected pedicels (17 taxa, 38\%; e.g. Fig. 2C). Egg bundles occur mainly in the P4 (G3 and G4) cluster. In clusters P1 (alcestes-group) and P3 (prasinus-group), only $P$. astur, $P$. formosanus, and $P$. marianus lay bundled eggs. All of the six species with a grey or brown body colour deposit whitish eggs, five in bundles, one singly.

\section{DISCUSSION}

The genus Pseudomallada, comprising at least 166 described species, vies with Leucochrysa MacLachlan as the largest genus in the Chrysopidae. Almost a third of those are species described from China in the years after 1988 (Dong et al., 2004). Of the remaining 110 species, more than a third were available for study here.

\section{THE FOUR PSEUDOMALLADA GROUPS}

Aspöck et al. (2001) considered the species-rich genus Pseudomallada (then Dichochrysa) in need of revision and suspected that it was not a monophyletic genus. Now we have evidence that the genus is monophyletic. Additionally, both molecular data and genital morphology support the same four distinct morphological species-groups within the genus. In only three cases, molecular analyses revealed singletons as sister taxa of molecular clades. In two of those, the shape of the gonapsis leans towards one of the four morphological groups. Thus, there are very few mismatches between molecularly determined clades and morphologically based gonapsis groups.

In most of the four species-groups, species distributions permit speculation on origins of the groups. The molecularly well-supported P1 clade most likely originated in Asia (P. astur, P. alcestes, P. sp. 1 and $P$. sp. 2, $P$. cognatellus, $P$. parabolus, $P$. formosanus, $P$. ussuriensis), with two independent range extensions into the Indian Ocean and Africa. Apertochrysa eurydera is present on most islands east of Africa and in eastern and northwestern parts of continental Africa. A small clade that includes the widespread species, $P$. sjostedti, also extends to the Mascarene Islands (P. duplicatus) and into southern Africa (P. pulchrinus).

The easily delineated prasinus-group (P3, G2) occurs mainly in Eurasia and northern Africa. Some of the species are difficult to identify reliably, especially the females. This might be the reason for the species names prasinus and abdominalis occurring several times on the list in Figure 1. We suspect that the prasinus-group comprises several undescribed cryptic species. In fact, Aspöck et al. (1980) reported that in large parts of northern Europe, $P$. prasinus and $P$. ventralis form mixed phenotypes. Additionally, the present study shows that except for $P$. benedictae, the species in the prasinus-group have similar DNA sequences for the three nuclear genes ( $P$-distances are less than 0.009; Table 4). Indeed, sequences for all three genes were nearly the same in Swiss $P$. prasinus and P. abdominalis, while Greek $P$. prasinus and Italian $P$. abdominalis had ATPase sequences identical to each other. We could not identify cryptic species within the prasinus-group. However, $P$. marianus is the only species within the prasinus-group to deposit its eggs in bundles, possibly confirming its validity as a separate, cryptic species (Duelli, 1994).

The flavifrons-group (part of P4, G3) is mainly African $[P$. hamatus, P. myassalandicus, $P$. handschini, $P$. chloris, $P$. spissinervis, $P$. sp. gray from South Africa, P. luaboensis, $P$. gunvorae, $P$. kibonotoensis, and $P$. baronissus (recently synonymized, probably prematurely, with P. kibonotoensis)]. However, one small, well-supported molecular clade has colonized North America (P. perfectus, P. macleodi, P. luctuosus), while another small clade, which includes the widespread 


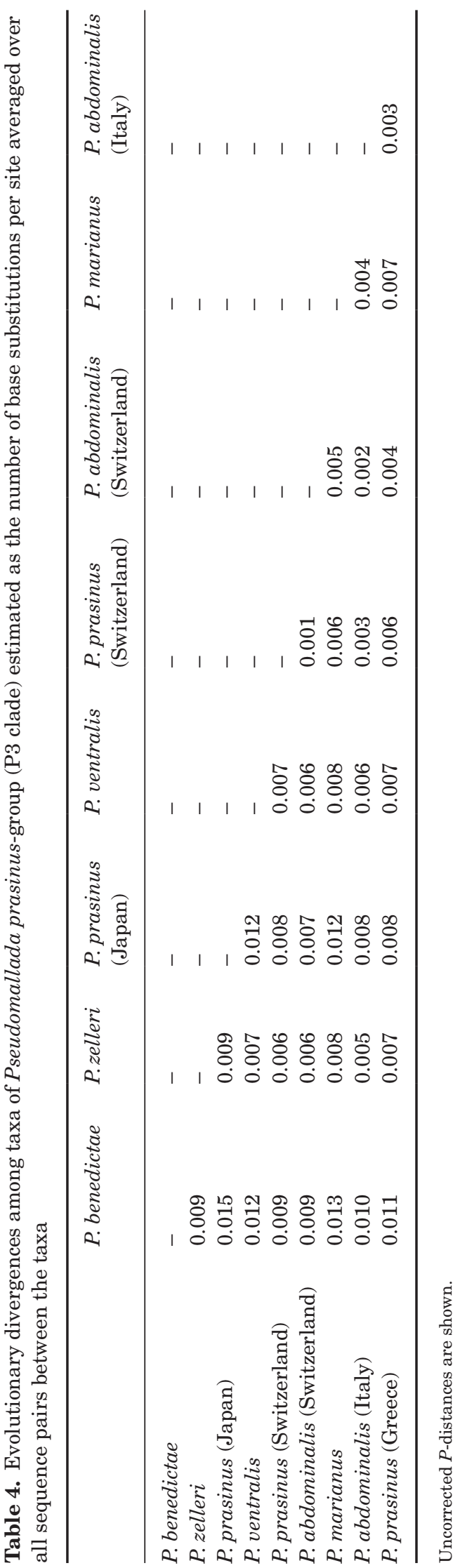

species $P$. flavifrons, extends across Europe (P. ibericus, P. picteti) and into Asia (P. flavifrons).

The venosus-group (P5, G4) may have its origin around the Mediterranean Sea $[P$. clathratus, $P$. genei, $P$. venosus (also in western Asia)], but one cluster of species extends into Africa (the widespread P. nicolai$n u s$, the undescribed $P$. sp. Sodere from Ethiopia) and even as far as South Africa (P. karooensis, P. rubicundus, P. tactus).

There are only a few singletons between the molecular clades:

Apertochrysa edwardsi is an Australian species. It clearly belongs to Pseudomallada based on molecular data, but it has no tignum. Therefore, it had been placed in the genus Apertochrysa, which Brooks \& Barnard (1990) reported as having a small, T-shaped gonapsis but no tignum. Apertochrysa eurydera similarly lacks a tignum but appears to be a member of the P1 molecular clade. It is clear that at least $A$. eurydera, and probably A. edwardsi, should be moved into Pseudomallada s.s., based on molecular data and the shape of the gonapsis. In fact, the gonapsis of A. edwardsi is very similar to that of $P$. alcestes and $P$. sjostedti. However, the gonapsis of A. eurydera, which is allied on molecular grounds with the alcestes-group, instead more closely resembles that of the flavifrons-group, or even that of $P$. inopinatus. In any case, our results suggest that the tignum is not definitive for the genus Pseudomallada, even though both structures are present in all species of Pseudomallada s.s. that we examined. Tsukaguchi's report of no gonapsis in Apertochrysa is probably in error, likely caused by accidental substitution of the word gonapsis for tignum on page 18 of his monograph (Tsukaguchi, 1995).

Three species of the genus Apertochrysa (A. albolineatoides Tsukaguchi, A. eurydera, and A. edwardsi) are presently scattered across the phylogenetic tree of the Chrysopidae (Fig. 1; Supporting Information, Figs S1 and S2; Haruyama et al., 2008). Apertochrysa albolineatoides appears within a clade that includes Cunctochrysa Hölzel and Meleoma Fitch (Haruyama et al., 2008), while we have shown here the likelihood that $A$. eurydera and A. edwardsi are part of Pseudomallada s.l. (Fig. 1). These results indicate that a comprehensive systematic revision of Apertochrysa is necessary (A. Mochizuki et al., in preparation).

Another singleton is P. inornatus, shown in Figure 1 as molecularly distinct from and the sister taxon to P2. The shape of its tiny gonapsis (Fig. 4B) is markedly different from that characterizing any other Pseudomallada species. Pseudomallada inornatus is known from Europe and the Caucasus.

Pseudomallada inopinatus, a rare endemic highland species on the island of La Réunion east of Madagascar, belongs to the species-rich clade $\mathrm{P} 4$, comprising mainly African species. It appears on the tree as an isolated 
sister taxon to clade P5. Its gonapsis (Fig. 4C), however, is unlike others in P5. The most similar gonapsis to that of $P$. inopinatus is found in species such as $P$. kibonotoensis, which belong to G4 but are still part of the P4 clade.

\section{ADAPTIVE COLORATION AND OVIPOSITION}

Not all 'green lacewings' are green. Some even change their body coloration during the adult's lifetime (Duelli, Johnson, et al., 2014). Variations in body coloration reflect cryptic adaptations to environmental conditions. A well-known characteristic of the genus Pseudomallada is the difference in body coloration among closely related species. From Figure 1 it is clear that in two groups (G1 and G2), all species are green, whereas in clade P4 (G3 and G4), some but not all species are grey or brown. These non-green species occur in different sub-clades, interspersed phylogenetically with green species. The conclusion is that green must have been the original body colour in Pseudomallada. Grey or brown body coloration, always linked with white or greyish eggs, and often with bundled egg pedicels, is a derived trait, developed independently in dry and hot habitats, where the vegetation is yellow, grey, or brown for most of the period when the adults are active. Even in a bluish-brownish species considered as green here ( $P$. clathratus), a yellow mutation occurs in the wild in dry areas (Duelli, 1994). In Europe, brownish-grey species such as $P$. venosus, $P$. genei, or $P$. venustus live only in the driest parts of the continent. Convergent evolution of grey or brown species in different genetic clusters leads to species that look very similar but have completely different shapes of their gonapses.

Not only the colour of the body and eggs is scattered among the phylogenetic clades but also the mode of egg deposition is polyphyletic. Clustered egg pedicels are particularly common in non-green lacewings, but they also occur in some green species in all groups. Depositing eggs singly or in bundles significantly influences the intensity of cannibalism (Duelli \& Johnson, 1992) and can be viewed as an adaptive trait (Duelli, 1981). In a habitat with sufficient food for most larvae, depositing eggs singly is a more successful way to produce offspring. With scarce food, isolated tiny larvae soon starve to death, while larvae from bundled eggs have a chance to encounter sibling larvae, which can be attacked and eaten. Laboratory experiments have shown that with scarce food, at least one larva out of a daily bundle of about 20 eggs will survive to the adult stage (Duelli \& Johnson, 1992). From the distribution within the clusters in Figure 1 of species with egg bundles, we cannot see an obvious link to particular habitat qualities, other than the observation that bundled eggs are more often deposited in species living in hot and dry climates. However, several green species living in rather lush habitat $(P$. astur, $P$. marianus, and the North American species) show that there must be other reasons than climate for egg bundles.

\section{ACKNOWLEDGEMENTS}

We thank the associates and funding sources of AM and MN for extraction and sequencing of lacewing DNA. We are indebted to Hideshi Naka (Tottori University, Japan) for contributing his molecular expertise and assistance. Additional thanks go to our valued colleagues, Mervyn Mansell (Pretoria) for organizing and leading trips to collect South African lacewings, and Maria L. Papas (Democritus University of Thrace, Greece) for providing Pseudomallada prasinus collected in Greece. We also thank the members of the Laboratory of Applied Entomology (Chiba University, Japan) for help with molecular work. The authors declare that they have no sources of conflict of interest.

\section{References}

Adams PA. 1975. Status of the genera Ungla and Mallada Navás (Neuroptera, Chrysopidae). Psyche 82: 167-173.

Adams PA, Garland JA. 1982. A review of the genus Mallada in the United States and Canada, with a new species (Neuroptera: Chrysopidae). Psyche 89: 239-248.

Anonymous. 2010. Opinion 2254 (Case 3399): Dichochrysa Yang, 1991 (Insecta, Neuroptera): generic name not conserved. Bulletin of Zoological Nomenclature 67: 261-262.

Aspöck H, Aspöck U, Hölzel H. 1980. Die Neuropteren Europas. Eine zusammenfassende Darstellung der Systematik, Ökologie und Chorologie der Neuropteroidea (Megaloptera, Raphidioptera, Planipennia) Europas. Krefeld: Goecke and Evers.

Aspöck H, Hölzel H, Aspöck U. 2001. Kommentierter Katalog der Neuropterida (Insecta: Raphidioptera, Megaloptera, Neuroptera) der Westpaläarktis. Denisia 2: 1-606.

Brooks SJ. 1994. A taxonomic review of the common green lacewing genus Chrysoperla (Neuroptera: Chrysopidae). Bulletin of the British Museum of Natural History (Entomology) 63: 137-210.

Brooks SJ, Barnard PC. 1990. The green lacewings of the world: a generic review (Neuroptera: Chrysopidae). Bulletin of the British Museum of Natural History (Entomology) 59: 117-286.

Brower AVZ, DeSalle R. 1998. Patterns of mitochondrial versus nuclear DNA sequence divergence among nymphalid butterflies: the utility of wingless as a source of characters for phylogenetic inference. Insect Molecular Biology 7: 73-82.

Dong K-Z, Li W-Z, Cui J-Z, Yang X-K. 2004. Three new species of Dichochrysa (Insecta: Neuroptera: Chrysopidae) from China, with a checklist of Chinese Dichochrysa. Raffles Bulletin of Zoology 52: 67-74. 
Duelli P. 1981. Is larval cannibalism in lacewings adaptive? Research in Population Ecology 23: 193-209.

Duelli P. 1984. Oviposition. In: Canard M, Séméria Y, New TR, eds. Biology of Chrysopidae. The Hague: Dr W. Junk, $129-133$.

Duelli P. 1994. Neuroptera from the Mediterranean islands of Malta (Neuroptera). Entomofauna 15: 125-128.

Duelli P, Henry CS, Mochizuki A. 2014. The endemic Atlantochrysa atlantica (McLachlan) (Neuroptera: Chrysopidae) on Atlantic Islands: African or American origin? Journal of Natural History 48: 2595-2608.

Duelli P, Johnson JB. 1992. Adaptive significance of the egg pedicel in lacewings (Neuroptera: Chrysopidae). In: Canard M, Aspöck H, Mansell MW, eds. Current research in neuropterology. Proceedings of the Fourth International Symposium on Neuropterology, Bagnères-de-Luchon, France, 1991. Toulouse: Sacco, 125-134.

Duelli P, Johnson JB, Waldburger M, Henry CS. 2014. A new look at adaptive body coloration and color change in "common green lacewings" of the genus Chrysoperla (Neuroptera: Chrysopidae). Annals of the Entomological Society of America 107: 382-388.

Edgar RC. 2004a. MUSCLE: a multiple sequence alignment method with reduced time and space complexity. $B M C$ Bioinformatics 5: 113.

Edgar RC. 2004b. MUSCLE: multiple sequence alignment with high accuracy and high throughput. Nucleic Acids Research 32: 1792-1797.

Felsenstein J. 1985. Confidence limits on phylogenies: an approach using the bootstrap. Evolution 39: 783-791.

Friedlander TP, Regier JC, Mitter C, Wagner DL. 1996. A nuclear gene for higher level phylogenetics: phosphoenolpyruvate carboxykinase tracks Mesozoic-age divergences within Lepidoptera (Insecta). Molecular Biology and Evolution 13: 594-605.

Haruyama N, Mochizuki A, Duelli P, Naka H, Nomura M. 2008. Green lacewing phylogeny, based on three nuclear genes (Chrysopidae, Neuroptera). Systematic Entomology 33: $275-288$.

Hölzel H. 1993. New Mallada species from southern Africa (Neuroptera: Chrysopidae).Zeitschrift der Arbeitsgemeinschaft Oesterreichischer Entomologen 45: 69-74.

Hölzel H, Ohm P. 1995. Vier neue Chrysopidae-Spezies aus der Madagassis (Neuroptera).Zeitschrift der Arbeitsgemeinschaft Österreichischer Entomologen 47: 112-118.
Hölzel H, Ohm P. 2000. Neue taxa der Chrysopidae aus der Madagassis (Neuroptera). Linzer Biologische Beitrage 32: $743-752$.

Lanfear R, Calcott B, Ho SY, Guindon S. 2012. PARTITIONFINDER: combined selection of partitioning schemes and substitution models for phylogenetic analyses. Molecular Biology and Evolution 29: 1695-1701.

Nakahara W. 1955. New Chrysopidae from Formosa. Kontyû 23: $143-147$.

Navás L. 1925. Discurso pronunciado sobre D. Lucas Mallada en el Homenaje al mismo celebrado en Huesca. Publicaciones de la Academia de Ciencias Exactas, Físico-Químicas y Naturales de Zaragoza 1925: 212-215.

New TR. 1980. A revision of the Australian Chrysopidae (Insecta, Neuroptera). Australian Journal of Zoology Supplementary Series 77: 1-143.

Rambaut A, Suchard MA, Xie D, Drummond AJ. 2014. Tracer, version 1.6. Available at: http://beast.bio.ed.ac.uk/ Tracer

Ronquist F, Teslenko M, van der Mark P, Ayres DL, Darling A, Höhna S, Larget B, Liu L, Suchard MA, Huelsenbeck JP. 2012. MrBayes 3.2: efficient Bayesian phylogenetic inference and model choice across a large model space. Systematic Biology 61: 539-542.

Stamatakis A. 2014. RAxML version 8: a tool for phylogenetic analysis and post-analysis of large phylogenies. Bioinformatics 30: 1312-1313.

Tamura K, Stecher G, Peterson D, Filipski A, Kumar S. 2013. MEGA6: Molecular Evolutionary Genetics Analysis version 6.0. Molecular Biology and Evolution 30: 2725-2729.

Tjeder B. 1966. Neuroptera, Planipennia. The lacewings of Southern Africa. 5. The family Chrysopidae. In: Hanström B, Brinck P, Rudebeck G, eds. South African animal life, 12. Stockholm: Swedish Natural Science Research Council, 228-534.

Tsukaguchi S. 1995. Chrysopidae of Japan (Insecta, Neuroptera). Osaka: Private Publication, Yutaka Insatsu Company.

Winterton S, de Freitas S. 2006. Molecular phylogeny of the green lacewings (Neuroptera: Chrysopidae). Australian Journal of Entomology 45: 235-243.

Yang X-K. 1991. Dichochrysa nom. nov. for Navasius Yang et Yang 1990 (Neuroptera: Chrysopidae) nec. Esben-Petersen 1936 (Neuroptera: Myrmeleonidae). In: Zhang G-X, ed. Scientific treatise on the systematic and evolutionary zoology. Beijing: Popular Science Press, 150.

\section{SUPPORTING INFORMATION}

Additional Supporting Information may be found in the online version of this article at the publisher's web-site:

Figure S1. Bayesian tree for all chrysopid taxa used in this study. The tree is inferred from a combined analysis of three nuclear genes. The total sequence length of the alignment was $1926 \mathrm{bp}$, comprising $483 \mathrm{bp}$ of PepCK, $525 \mathrm{bp}$ of $w g$, and $918 \mathrm{bp}$ of ATPase. Values placed on each node are Bayesian posterior probabilities $\geq 0.80$.

Figure S2. Maximum likelihood tree for all chrysopid taxa used in this study. The tree is inferred from a combined analysis of three nuclear genes. The total sequence length of the alignment was $1926 \mathrm{bp}$, comprising $483 \mathrm{bp}$ of PepCK, $525 \mathrm{bp}$ of $w g$, and $918 \mathrm{bp}$ of ATPase. Values placed on each node are ML bootstrap values $\geq 50 \%$. 